\title{
Attitude and Vaccination Status of Healthcare Workers against Hepatitis B Infection in a Teaching Hospital, Ethiopia
}

\author{
Mohammed Akibu $\left(\mathbb{D},{ }^{1}\right.$ Sodere Nurgi, ${ }^{1}$ Mesfin Tadese $\mathbb{D}^{D},{ }^{1}$ and Wendwesen Dibekulu Tsega ${ }^{2}$ \\ ${ }^{1}$ Department of Midwifery, Institute of Medicine and Health Science, Debre Berhan University, Debre Berhan, Ethiopia \\ ${ }^{2}$ Department of Public Health, Institute of Medicine and Health Science, Debre Berhan University, Debre Berhan, Ethiopia \\ Correspondence should be addressed to Mohammed Akibu; mahammedakibu@gmail.com
}

Received 4 November 2017; Revised 5 February 2018; Accepted 1 March 2018; Published 2 April 2018

Academic Editor: Paulo Hilário Nascimento Saldiva

Copyright (c) 2018 Mohammed Akibu et al. This is an open access article distributed under the Creative Commons Attribution License, which permits unrestricted use, distribution, and reproduction in any medium, provided the original work is properly cited.

\begin{abstract}
Background. World Health Organization and Centers for Disease Control and Prevention recommend all health professionals to get vaccinated against hepatitis B virus before they start the clinical attachments during their stay in the medical school. However, only $18-39 \%$ of healthcare workers in low- and middle-income countries received the vaccine. Therefore, this study aims to determine the attitude and vaccination status of health professionals working at Adama General Hospital and Medical College. Methods. An institution-based cross-sectional study was conducted from December 2016 to February 2017 with 403 health professionals working at Adama General Hospital and Medical College. Data were collected using self-administered questionnaire distributed at the participant's work unit and analyzed using SPSS version 20. Multiple logistic regression analysis was conducted to identify factors that affect the complete vaccination status and $p$ value $<0.05$ was considered statistically significant. Result. The prevalence of complete vaccination against hepatitis B virus was $25.6 \%$. The most frequently mentioned reasons for not being vaccinated were high cost of the vaccine $(41 \%)$ and unavailability of the vaccine (36\%). More than three-fourths (77.8\%) of study participants strongly agreed that hepatitis B is a major public health threat and there was tendency among participants to believe that their profession will put them at increased risk of acquiring the disease (strongly agreed: 75.9\%). Attending infection-prevention training [AOR $=$ 2.3; 95\% CI, 1.24-6.31], history of exposure to risky behavior [AOR $=5.5 ; 95 \%$ CI, 2.86-9.29], and long years of work experience $[\mathrm{AOR}=3.1 ; 95 \% \mathrm{CI}, 1.98-5.24]$ were statistically significant with complete vaccination status. Conclusion. Only one-quarter of health professionals received the recommended full dose of the vaccine. Sustained hepatitis B vaccination programs for healthcare workers need to be established by collaboration of different stakeholders to optimize health professionals' safety against this contagious infection.
\end{abstract}

\section{Introduction}

Hepatitis B infection has been a major public health threat that affects nearly two billion people worldwide with 350 million chronic cases and more than 2 million deaths every year [1]. The disease is mainly transmitted by percutaneous or mucosal exposure to infected blood or other bodily fluids and numerous forms of human contact have been suggested to transmit hepatitis B virus (HBV): perinatal/mother-to-child, nonsexual, sexual, needle-sharing, and occupational/healthcare-related forms [2]. The disease causes chronic infection, resulting in cirrhosis of the liver, liver cancer, liver failure, and death.
Furthermore, extrahepatic lesions can occur in other organs of the body, particularly in the kidney [3].

Since contact with body fluid of an infected person is one of the principal modes of transmission of the causative virus of hepatitis B infection, healthcare workers (HCWs) constitute one of the high-risk groups for this infection because of their repeated exposure [4]. World Health Organization (WHO) estimated that, of the 35 million HCWs worldwide, 3 million experience percutaneous exposure to blood pathogens each year and 2 million of those HCWs are exposed to hepatitis B virus [5-8]. In general, prevalence of HBV infection among healthcare providers is approximately ten times greater than the general population [9]. More 
importantly, HCWs in developing countries are at serious risk of infection from blood-borne pathogens because of the high prevalence of such pathogens in many poorer regions of the world, especially in endemic areas like Sub-Saharan Africa [10].

Due to the absence of medical treatment that can cure hepatitis $B$ virus (HBV) infection, hepatitis $B$ vaccine is the single most effective and safe strategy for the prevention of the disease if appropriate doses are given during a period of 6 months. The vaccine provides more than $90 \%$ effective protection after all doses [11, 12]. As part of occupational safety measures, WHO, Centers for Disease Control and Prevention (CDC), and the Ethiopian Federal Ministry of Health $(\mathrm{FMOH})$ infection-prevention guidelines recommend that all health professionals should be vaccinated against HBV before they started the clinical attachments during their stay in the medical school [13-15]. However, in spite of higher vulnerability among health professionals, the WHO estimate showed that $\mathrm{HBV}$ vaccination coverage among HCWs is only $18-39 \%$ in low- and middle-income countries compared to $67-79 \%$ in developed countries [13].

In Ethiopia, hepatitis B infection cases account for $12 \%$ of the hospital admissions and $31 \%$ of the mortality in medical wards of Ethiopian hospitals [16]. Specifically, studies conducted on health professionals revealed $9.7 \%$ prevalence of hepatitis B surface antigen (HBsAg) [17]. On top of that, some studies also reported lower coverage of hepatitis B vaccination among health professionals [18-21]. Therefore, this study aimed to assess the attitude and vaccination status of health professionals against hepatitis B virus infection and factors associated with complete immunization.

\section{Methods}

2.1. Study Design and Setting. The study was conducted at Adama General Hospital and Medical College, Adama, Ethiopia. The city is located $99 \mathrm{~km}$ away from Addis Ababa, the capital city of Ethiopia, to the southeast. This teaching hospital has catchment population of about 5 millions, serving as referral hospital for all nearby hospitals and adjacent regions. It has more than 500 healthcare workers providing the service in different units. This is an institution-based cross-sectional study conducted from December 2016 to February 2017.

2.2. Study Participants. All health professionals working at Adama General Hospital and Medical College were included into the study irrespective of their working unit and duration of stay to minimize the risk of selection bias.

2.3. Variables and Measurement. Complete immunization against hepatitis B virus and attitude of healthcare workers towards hepatitis B infection and its vaccination were the outcome variables measured in the study, whereas various sociodemographic variables (age, profession, working unit, and years of work experience) and occupational variables (training on infection-prevention and history of exposure to risky behavior) were the independent variables. Complete immunization was measured using the following question: "how many doses of the vaccine have you taken?" Taking three or more doses of the vaccine was defined as complete immunization. Attitude was measured on the cumulative score of thirteen questions designed to assess healthcare workers' attitude towards hepatitis B infection and its vaccination. Each attitude question contains ordinal categorical response rated in 5-point Likert scale [i.e., $1=$ strongly disagree; 5 = strongly agree $]$ and these questions were adapted from previous literatures $[19,22,23]$. Overall, the scores for each participant were summed and study participants who have responded to $\geq 60 \%$ of attitude questions positively were regarded as having favorable attitude.

2.4. Sample Size and Sampling Procedure. Single population proportion formula was used to calculate the sample size given the prevalence of hepatitis B vaccination for healthcare workers of $50 \%$ to obtain a relatively larger sample size, confidence level of $95 \%$, and marginal error of $5 \%$. The final sample size was 403 after adjustment for 5\% nonrespondent rate. The total sample size was proportionally allocated to each of the working departments in the hospital. The list of health professionals working in each department was obtained from the hospital and simple random sampling technique was employed to select the study subjects from the list.

2.5. Data Collection and Quality Control. Data were collected using self-administered questionnaire distributed at the participant's work unit. Data collection was performed by three nursing professionals through distributing and recollecting the questionnaire prepared in English. Pretesting was performed on $5 \%$ of the total sample size in other health facilities and a necessary adjustment was made prior to the actual data collection. The questionnaire was also tested for internal consistency (reliability) by Cronbach's Alpha test using Statistical Package for Social Sciences (SPSS) version 20.0. Similarly, content validity was cross-checked by a public health expert. The completeness, consistency, and accuracy of the collected data were examined by principal investigator every day.

2.6. Data Processing and Analysis. The data were coded, cleaned, and entered into Epi Info version 7 and it was exported to SPSS version 20 for statistical analysis. First, descriptive statistics were generated followed by binary and multiple logistic regressions to examine the possible association between the determinant and the outcome variable. In this model, $P$ value $<\mathbf{0 . 0 5}$ was used to declare the presence of statistically significant association. The result was reported strictly following STrengthening the Reporting of OBservational Studies in Epidemiology (STROBE) statement (supplementary file (available here)).

\section{Result}

3.1. Sociodemographic Characteristics of the Study Participants. A total of 386 participants completed the questionnaire, making a response rate of $97 \%$. More than half (198 $(51.2 \%))$ of participants were male and the age of study 
TABLE 1: Socio-demographic characteristics of health professionals, AHMC, Ethiopia 2017.

\begin{tabular}{|c|c|c|}
\hline Variable & Frequency $(n=386)$ & Percent (\%) \\
\hline \multicolumn{3}{|l|}{ Sex } \\
\hline Male & 198 & 51.2 \\
\hline Female & 188 & 48.8 \\
\hline \multicolumn{3}{|l|}{ Age (years) } \\
\hline 20-30 & 33 & 16.3 \\
\hline $31-40$ & 94 & 46.3 \\
\hline$>40$ & 7 & 3.4 \\
\hline \multicolumn{3}{|l|}{ Marital status } \\
\hline Unmarried & 210 & 54.4 \\
\hline Married & 176 & 45.6 \\
\hline \multicolumn{3}{|l|}{ Religion } \\
\hline Orthodox & 266 & 69 \\
\hline Protestant & 72 & 18.7 \\
\hline Muslim & 35 & 8.9 \\
\hline Other $^{\mathrm{a}}$ & 13 & 3.4 \\
\hline \multicolumn{3}{|l|}{ Profession } \\
\hline Nurse & 203 & 52.7 \\
\hline Midwife & 44 & 11.3 \\
\hline Lab technician & 25 & 6.4 \\
\hline General Practitioner & 52 & 13.5 \\
\hline Dental Doctor & 14 & 3.6 \\
\hline Pharmacist & 20 & 5.2 \\
\hline Specialist & 28 & 7.3 \\
\hline \multicolumn{3}{|l|}{ Working department } \\
\hline Inpatient department & 92 & 23.8 \\
\hline Outpatient & 114 & 29.5 \\
\hline Emergency department & 36 & 9.3 \\
\hline Delivery unit & 53 & 13.8 \\
\hline Laboratory & 28 & 7.3 \\
\hline OR department & 32 & 8.3 \\
\hline Dental department & 31 & 8 \\
\hline \multicolumn{3}{|l|}{ Work experience } \\
\hline$<5$ years & 227 & 58.7 \\
\hline$\geq 5$ years & 159 & 41.3 \\
\hline \multicolumn{3}{|c|}{ Training on infection prevention } \\
\hline Yes & 224 & 58 \\
\hline No & 162 & 42 \\
\hline
\end{tabular}

${ }^{\mathrm{a}}$ catholic, woke feta, Adventist.

participants ranged from 21 to 64 with the mean age of 28.45 $( \pm 3.2)$ years. The professional background of respondents was dominated by nurses $(203(52.7 \%))$ followed by medical doctors (52 (13.5\%)) (Table 1).

3.2. Attitude towards Hepatitis B Infection and Its Vaccination. More than three-fourths (77.8\%) of study participants strongly agreed that hepatitis B is a major public health threat. Similarly, more than half $(51.2 \%)$ of healthcare workers strongly agreed that hepatitis B vaccine should be obligatory to take. There was tendency among participants to believe that their profession will put them at increased risk of acquiring the disease (strongly agreed: 75.9\%). Participants also stated that following the infection-prevention guideline has a potential benefit on reducing the chance of contracting hepatitis B infection (strongly agreed and agreed: $85.2 \%$ ) (Table 2).

3.3. History of Occupational Exposure and Perceived Risk of Disease Acquisition. Healthcare workers were asked to rate their perceived risk of acquiring the infection. The respondents reported that they have very high (51 (13.3\%)), high $(80(20.7 \%))$, medium (101 (26.1\%)), low (142 (36.9\%)), and very low $(12(3 \%))$ risk of contracting the disease. Nearly half $(182(47.3 \%))$ of healthcare workers had history of occupational exposure to risky conditions. Unprotected mucocutaneous fluid contact on intact skin (121 (66.7\%)), sharp-needle injury (72 (39.6\%)), and body fluid splash through body openings (51 (28.1\%)) represent the three main forms of exposure. The most common (130 (71.3\%)) action taken after the exposure was washing the area of exposure with soap, water, or antiseptic (Table 3 ).

3.4. Vaccination and Postvaccination Testing. Only three in ten $(118(30.4 \%))$ participants had been screened for hepatitis B surface antigen. Regarding the vaccination status of study participants, more than half $(223(57.7 \%))$ of them reported history vaccination at least once. However, less than half (99 $(44.5 \%))$ of these participants received the recommended three doses of the vaccine, of which 36 (36.8) tested after the vaccine to check for the vaccine effect and all of them were protected (anti-HB titer $>10 \mathrm{MIU} / \mathrm{ml}$ ). Among healthcare workers who did not take the vaccine, vaccine unavailability through government channels (36\%), high cost of the vaccine for private access $(41 \%)$, and not giving much concern about this issue $(26 \%)$ represent the major reasons stated for not being vaccinated (Table 4$)$.

3.5. Factors Associated with Vaccination Status. Multivariate analysis of factors affecting the practice of full dose vaccination revealed that previous exposure to occupational risks of hepatitis B infection, years of work experience and infection-prevention training were statistically significant with complete vaccination status. Participants whose years of work experience were $\geq 5$ years had 3 times $(\mathrm{AOR}=3.1$ (.98-5.24)) greater chance of receiving the vaccine. Likewise, previous history of exposure to occupational risks of hepatitis $\mathrm{B}$ infection resulted in 5.5 times $(\mathrm{AOR}=5.5(2.86-9.29)$ ) increased practice of receiving full dose vaccine. Similarly, participants who attended infection-prevention training were 2.3 times $(\mathrm{AOR}=2.3(1.24-6.31))$ more likely to take the recommended vaccine dose than their counterparts (Table 5).

\section{Discussion}

Hepatitis B vaccination is one of the most important primary prevention ways of this contagious disease and immunization against this infectious agent provides an optimal protection for individuals at risk [24]. World Health Organization estimated that hepatitis B vaccine's coverage among healthcare providers is $18 \%$ in Africa, which represents the least 
TABLE 2: Attitude of health professional towards hepatitis B infection and its vaccination, AHMC, Ethiopia, in 2017.

\begin{tabular}{|c|c|c|c|c|c|}
\hline Items & Strongly agree & Agree & Neutral & Disagree & Strongly Disagree \\
\hline $\mathrm{HBV}$ is serious public health problem & $300(77.8 \%)$ & $70(18.2 \%)$ & $4(1.0 \%)$ & $10(2.5 \%)$ & $2(0.5 \%)$ \\
\hline $\begin{array}{l}\text { All patients should be tested for HBV before they receive } \\
\text { healthcare }\end{array}$ & $80(20.7 \%)$ & $116(30.1 \%)$ & $99(25.6 \%)$ & $68(17.7 \%)$ & $23(5.9 \%)$ \\
\hline $\begin{array}{l}\text { Being a health professional puts you at greatest risk of } \\
\text { HBV infection }\end{array}$ & $292(75.9 \%)$ & $80(20.6 \%)$ & $8(2 \%)$ & $4(1 \%)$ & $2(0.5 \%)$ \\
\hline $\begin{array}{l}\text { Following infection control guidelines will protect me } \\
\text { from being infected with } \mathrm{HBV} \text { and } \mathrm{HCV} \text { at work }\end{array}$ & $203(52.7 \%)$ & $125(32.5 \%)$ & $21(5.4 \%)$ & $29(7.4 \%)$ & $8(2,0 \%)$ \\
\hline $\begin{array}{l}\text { I deliver the same standard of care to patients with } \mathrm{HBV} \\
\text { as I do for other patients }\end{array}$ & $46(11.8 \%)$ & $148(38.4 \%)$ & $32(8.4 \%)$ & $101(26.1 \%)$ & $59(15.3 \%)$ \\
\hline $\begin{array}{l}\text { It is appropriate not to spend much time when caring } \\
\text { HBV-infected patients }\end{array}$ & $91(23.6 \%)$ & $109(28.2 \%)$ & $46(11.8 \%)$ & $72(18.7 \%)$ & $68(17.7 \%)$ \\
\hline A healthcare worker can infect patients with $\mathrm{HBV}$ & $112(29.1 \%)$ & $141(36.5 \%)$ & $15(3.9 \%)$ & $78(20.2 \%)$ & $40(10.3 \%)$ \\
\hline $\begin{array}{l}\text { Health professionals who are hepatitis B virus-positive } \\
\text { should not give healthcare services to patients }\end{array}$ & $25(6.4 \%)$ & $32(8.4 \%)$ & $63(16.3 \%)$ & $118(30.5 \%)$ & $148(38.4 \%)$ \\
\hline I do not trust $\mathrm{HBV}$ vaccine & $17(4.3 \%)$ & $45(11.7 \%)$ & $54(14 \%)$ & $109(28.3 \%)$ & $161(41.7 \%)$ \\
\hline HBV vaccine should be compulsory & $198(51.2 \%)$ & $91(23.7 \%)$ & $25(6.4 \%)$ & $64(16.7 \%)$ & $8(2 \%)$ \\
\hline $\mathrm{HB}$ vaccine is safe but is expensive & $236(61.1 \%)$ & $89(23.2 \%)$ & $36(9.4 \%)$ & $13(3.4 \%)$ & $12(3.0 \%)$ \\
\hline $\begin{array}{l}\text { After exposure to contagious flu-id/ material, the vaccine } \\
\text { reduces likelihood of being HBV-positive }\end{array}$ & $122(31.5 \%)$ & $97(25.1 \%)$ & $49(12.8 \%)$ & $80(20.7 \%)$ & $38(9.9 \%)$ \\
\hline
\end{tabular}

TABLE 3: Exposure to occupational risk of hepatitis B among health professionals, AHMC, Ethiopia, in 2017.

\begin{tabular}{lcc}
\hline Variable & Frequency & \\
\hline Occupational exposure & & Percentage \\
Yes & 204 & \\
No & \\
Exposure to sharp injury & 72 \\
Yes & 110 \\
No & \\
Unprotected mucocutaneous fluid contact on intact skin & 121 \\
Yes & 61 \\
No & \\
Body fluid contact through body openings & 51 \\
Yes & 131 \\
No & \\
Measure taken after exposure & 71 \\
Testing the patient right away & 130 \\
Washing with soap, water, or antiseptic & 80 \\
Immediate report & 28.3 \\
Allowing the injury area to bleed & 25 \\
Wait and test myself & 11 \\
\hline
\end{tabular}

figure [25]. Therefore, this study assessed the coverage of hepatitis B vaccine among healthcare workers of Adama General Hospital and Medical College, Ethiopia.

In this study, it appeared that the proportion of healthcare workers who received hepatitis B vaccine at least once was $57.7 \%$. This finding is in the range of $47 \%-60 \%$ reported in different studies of different areas [20, 26-28]. However, the result is relatively lower compared to the findings reported from Iraq (65.7\%), Kuwait (74.4\%), India (78\%), and Nigeria $(91.9 \%)$ [29-32]. The complete reason for low vaccine coverage of our survey compared to these studies cannot be completely discernible. However, difference in vaccine accessibility across countries, relatively late addition of hepatitis $B$ vaccine into national immunization program, and certain variability between the sociodemographic characteristics of the study participants might explain this discrepancy. The proportion of healthcare workers who completed the recommended three or more doses of the vaccine constitutes $25.6 \%$ of the whole study participants. This figure is lower compared to reports of other studies conducted in Pakistan (57.6\%), 
TABLE 4: Vaccination status and reason for not taking the vaccine among health professionals, AHMC, Ethiopia, in 2017.

\begin{tabular}{|c|c|c|}
\hline Variables & $\begin{array}{c}\text { Frequency } \\
N\end{array}$ & $\begin{array}{c}\text { Percentage } \\
(\%)\end{array}$ \\
\hline \multicolumn{3}{|l|}{ Ever screened for hepatitis B } \\
\hline Screened & 118 & 30.4 \\
\hline Not screened & 268 & 69.6 \\
\hline \multicolumn{3}{|l|}{ Vaccination for hepatitis B } \\
\hline Vaccinated & 223 & 57.7 \\
\hline Not vaccinated & 163 & 42.3 \\
\hline \multicolumn{3}{|l|}{ Vaccination dose } \\
\hline Once only (incomplete vaccination) & 75 & 33.6 \\
\hline $\begin{array}{l}\text { Received two doses (incomplete } \\
\text { vaccination) }\end{array}$ & 49 & 21.9 \\
\hline $\begin{array}{l}\text { Three complete doses (fully } \\
\text { vaccinated) }\end{array}$ & 99 & 44.5 \\
\hline \multicolumn{3}{|l|}{ Complete vaccination status } \\
\hline Fully vaccinated & 99 & 44.5 \\
\hline Incomplete vaccination & 124 & 55.4 \\
\hline \multicolumn{3}{|l|}{ Have you been tested after full dose? } \\
\hline Tested for the vaccine effect & 36 & 36.4 \\
\hline Not tested & 63 & 63.8 \\
\hline \multicolumn{3}{|l|}{ Test result } \\
\hline Protected (anti-HB titer $>10 \mathrm{MIU} / \mathrm{ml})$ & 36 & 100 \\
\hline \multicolumn{3}{|l|}{ Reason for incomplete vaccination } \\
\hline Being busy & 47 & 37.9 \\
\hline I feel I am protected & 15 & 12.2 \\
\hline Forget it at all & 28 & 22.6 \\
\hline Waiting for the next dose & 34 & 27.3 \\
\hline \multicolumn{3}{|l|}{ Reason for not taking the vaccine } \\
\hline $\begin{array}{l}\text { The vaccine was not available through } \\
\text { government channels }\end{array}$ & 59 & 36 \\
\hline $\begin{array}{l}\text { The vaccine is very expensive for } \\
\text { private access }\end{array}$ & 67 & 41 \\
\hline I did not give it too much emphasis & 42 & 26 \\
\hline The side effect would be worse & 13 & 8 \\
\hline The duration of total dose is too long & 25 & 15.4 \\
\hline Others $^{\mathrm{b}}$ & 6 & 3.7 \\
\hline
\end{tabular}

${ }^{\mathrm{b}}$ I do not think I am at risk, I never thought about it, or I have no reason.

Malaysia (58.6\%), and Libya (72\%) [33-35]. This lower rate of complete immunization reflects the need for well effective strategy that enhances increased rate of compliance with recommended vaccine doses. Furthermore, health professionals have to be supported and inspired to check their protection status to make sure whether or not they require additional doses of the vaccine to get protected.

Regarding the attitude of healthcare workers towards hepatitis B infection and its vaccination, the majority of them showed encouraging positive attitude towards the issue. The majority $(77.8 \%)$ of healthcare workers strongly agreed that hepatitis B is a major public health threat and almost all (96.5\%) of them stated that their job puts them at risk of acquiring the disease. Regarding the importance of vaccination, around $75 \%$ of healthcare workers agreed that hepatitis B vaccination should be compulsory. These statements are also similarly reported at comparable rate in other studies conducted in Kuwait and Gondar University Hospital [30, 36].

Among healthcare workers who did not receive the vaccine, the most frequently mentioned reason was high cost of the vaccine for private access. Similarly, studies from different areas reported the same finding $[20,22,37$, 38]. Another barrier mentioned was vaccine unavailability, which was reported by $36 \%$ of participants. Likewise, this report is in line with the reasons mentioned for vaccine refusal in different articles [19, 28, 39]. This is an input for stakeholders to establish an effective program that focuses on vaccine availability at affordable cost to meet the demand of healthcare workers. According to our study, nearly half (47.3\%) of healthcare workers have been exposed to risky situation for hepatitis B infection. Of these, 39.6\% reported exposure to sharp-needle injury. A study conducted in Pakistan reported that the percentage of healthcare workers who had experienced at least one sharp injury in a year was $44 \%$ and another study conducted in Gondar University Hospital also revealed that $49.2 \%$ of healthcare workers had been exposed to occupational risks $[36,40]$. This evidence emphasizes the importance of hepatitis $B$ vaccination for this group of people in particular given the extent of their exposure.

This study revealed that healthcare workers who have been exposed to risky conditions of hepatitis B virus had increased chance of receiving complete immunization. This finding is in line with reports from north India, Zambia, and northwest Pakistan [23, 28, 41]. This might be because of increased perceived threat of getting such blood-borne disease after exposure to risky conditions. Years of work experience were another important factor that influenced the complete vaccination status of healthcare workers. Similarly, other studies showed that there was an increased chance to get full vaccination with increasing number of years of work experience [21, 42, 43]. This might be because of the fact that healthcare workers who joined the institutions later might not have benefited from vaccination because of sporadic availability of the vaccine through government channels. Likewise, increased length of work years would result in higher rate of exposure to various risky behaviors, which in turn leads to increased perceived threat of acquiring the disease. Participants who attended infection-prevention training showed increased rate of complete immunization. Studies from Zambia and Nigeria revealed the same finding [23]. This result shows that provision of basic infectionprevention training for all hospital might have a benefit in terms of lifting up the perceived benefit of such preventive strategies among healthcare workers.

\section{Limitations}

Despite extensive efforts that have been made to minimize possible shortcoming of this study, the finding of this survey 
TABLE 5: Logistic regression of factors affecting full vaccination status among HCWs who received at least one dose, AMHC, Ethiopia, in 2017.

\begin{tabular}{|c|c|c|c|c|}
\hline \multirow{2}{*}{ Variable } & \multicolumn{2}{|c|}{ Fully vaccinated } & \multirow{2}{*}{ COR (95\% CI) } & \multirow{2}{*}{ AOR $(95 \% \mathrm{CI})$} \\
\hline & Yes & No & & \\
\hline \multicolumn{5}{|l|}{ Sex } \\
\hline Male & 37 & 49 & 1 & 1 \\
\hline Female & 62 & 75 & $3.45(1.82-6.7)$ & $1.06(0.84-3.62)$ \\
\hline \multicolumn{5}{|l|}{ Work experience } \\
\hline$<5$ years & 28 & 74 & 1 & 1 \\
\hline$\geq 5$ years & 71 & 50 & $4.8(2.64-7.44)^{*}$ & $3.1(1.98-5.24)^{*}$ \\
\hline \multicolumn{5}{|l|}{ Profession } \\
\hline Nurse & 35 & 45 & $0.87(0.67-2.13)$ & $0.22(0.03-1.45)$ \\
\hline Midwife & 14 & 17 & $1.5(0.68-2.75)$ & $0.6(0.07-4.64)$ \\
\hline Lab technician & 12 & 13 & $2.6(1.36-5.71)^{*}$ & $1.72(0.89-2.42)$ \\
\hline General practitioner & 16 & 19 & $2.1(0.92-6.37)$ & $0.03(0.04-2.21)$ \\
\hline Pharmacist & 5 & 8 & $1.65(0.401-4.62)$ & $0.82(0.27-3.91)$ \\
\hline Dental doctor & 6 & 9 & $1.39(0.44-3.64)$ & $1.57(0.38-6.19)$ \\
\hline Specialist & 11 & 13 & 1 & 1 \\
\hline \multicolumn{5}{|l|}{ Training on IP } \\
\hline Yes & 67 & 48 & $3.4(2.77-8.92)^{*}$ & $2.3(1.24-6.31)^{*}$ \\
\hline No & 32 & 76 & 1 & 1 \\
\hline \multicolumn{5}{|l|}{ Work unit } \\
\hline Inpatient unit & 12 & 25 & $2.93(2.91-7.68)$ & $1.07(0.94-3.75)$ \\
\hline Dental department & 4 & 11 & $0.063(0.0057-0.84)$ & $0.071(0.003-1.83)$ \\
\hline Emergency unit & 13 & 16 & $1.4(0.63-3.18)$ & $1.6(0.71-4.2)$ \\
\hline Delivery unit & 23 & 21 & $4.64(1.43-19.7)^{*}$ & $2.48(0.82-7.29)$ \\
\hline Laboratory & 21 & 7 & $5.45(1.74-9.27)^{*}$ & $2.16(0.018-6.23)$ \\
\hline OR department & 6 & 13 & $1.39(0.34-3.24)$ & $1.56(0.40-6.24)$ \\
\hline Outpatient unit & 20 & 31 & 1 & 1 \\
\hline \multicolumn{5}{|l|}{ Exposure history } \\
\hline Yes & 73 & 38 & $6.4(3.43-11.58)$ & $5.5(2.86-9.29)^{*}$ \\
\hline No & 26 & 86 & 1 & 1 \\
\hline
\end{tabular}

* indicates statistically significant value.

will be interpreted in the presence of the following inevitable limitations. The cross-sectional nature of the study does not confirm the definitive cause-and-effect relationship. There is also a possibility of admitting recall bias because of the selfreported vaccination status.

\section{Conclusion}

Only a small proportion of healthcare workers have taken the recommended three doses of the vaccine at Adama General Hospital and Medical College. Attending infectionprevention training, work experience, and history of exposure to risky condition were the factors that are statistically significant with the completion of the recommended three doses. High cost of the vaccine for private access and vaccine unavailability were the major barriers identified for hepatitis $B$ vaccination. Sustained HBV vaccination programs for HCWs need to be established by collaboration of different stakeholders. Moreover, the Regional Health Bureau should offer the vaccine to HCWs free of charge by coordinating efforts from other concerned bodies. Similarly, the government should design a national strategy that focuses on vaccinating medical and health science students before they are assigned to their work place.

\section{Data Availability}

The original raw data analyzed during the current study is available from the corresponding author and can be presented upon reasonable request.

\section{Ethical Approval}

Ethical clearance was obtained from the Ethical Review Committee of Institute of Medicine and Health Science, University of Debre Berhan.

\section{Consent}

The respondents were informed about the purpose of the study and their consent to participate was obtained. 


\section{Conflicts of Interest}

The authors declare that they have no conflicts of interest.

\section{Authors' Contributions}

Mohammed Akibu designed the study, supervised the data collection, performed analysis and interpretation of data, and organized the paper and all versions of the manuscript. Sodere Nurgi, Mesfin Tadese, and Wendwesen Dibekulu Tsega were actively involved in supervision of the data collection, data analysis, and preparation of this manuscript. All authors read and approved the final manuscript.

\section{Acknowledgments}

The authors would like to pass their gratitude to the University of Debre Berhan for the ethical clearance. They also want to send their appreciation to the study participants for giving their genuine information.

\section{Supplementary Materials}

Supplementary file 1: completed checklist of STrengthening the Reporting of OBservational Studies in Epidemiology (STROBE) for cross-sectional studies. STROBE Statement-Checklist: Attitude and Vaccination status of Health care workers against Hepatitis B infection in a Teaching Hospital, Ethiopia. (Supplementary Materials)

\section{References}

[1] World Health Organization (2011) Hepatitis B, Fact sheet no: 204, 2011, http://www.who.int/mediacentre/factsheets/fs204/ en.

[2] R. Koff, "Immunologically mediated extra hepatic manifestations of viral hepatitis," in Autoimmune liver disease, EL. Krawitt and RH. Wiesner, Eds., Raven, New York, 1991.

[3] D. Lavanchy, "Hepatitis B virus epidemiology, disease burden, treatment, arid current and emerging prevention and control measures," Journal of Viral Hepatitis, vol. 11, no. 2, pp. 97-107, 2004.

[4] J. A. Molinari, "Infection control: Its evolution to the current standard precautions," The Journal of the American Dental Association, vol. 134, no. 5, pp. 569-574, 2003.

[5] M. J. Awases, A. G. Nyoni, and R. Chatora, Migration of health professionals in six countries: a synthesis report, Brazzaville: World Health Organization Regional Office for Africa, 2004.

[6] Centers for Disease Control and Prevention, Division of Health Care Quality Promotion. Surveillance of healthcare personnel with HIV/AIDS, http://www.cdc.gov/ncidod/hip/BLOOD/ hivpersonnel.htm.

[7] Canadian Center for Occupational Health and Safety, Needle sticks and sharps injuries, http://www.ccohs.ca/oshanswers/ diseases/needlestick_injuries.html.

[8] Centers for Disease Control and Prevention, "CDC guidance for evaluating health-care personnel for hepatitis b virus protection and for administering post exposure management," Morbidity and Mortality Weekly Report (MMWR) 10, 2013.

[9] Y. Zeleke, E. Tadese, and T. Gebeyaw, "Managements of exposure to blood and body fluids among healthcare workers and medical students in university of Gondar hospital, Northwest of Ethiopia," The Global Journal of Medical Research, vol. 13, no. $5,2013$.

[10] CDC, Hepatitis B Information for the Public, Atlanta: CDC Department of Viral Hepatitis, 2009.

[11] S. Colin, E. P. Simard, L. Finelli, A. E. Fiore, and B. P. Bell, "Hepatitis B virus infection: epidemiology and vaccination," Epidemiologic Reviews, vol. 28, no. 1, pp. 112-125, 2006.

[12] J. J. Ott, G. A. Stevens, J. Groeger, and S. T. Wiersma, "Global epidemiology of hepatitis B virus infection: new estimates of age-specific HBsAg seroprevalence and endemicity," Vaccine, vol. 30, no. 12, pp. 2212-2219, 2012.

[13] R. Thomas, Frieden. et al., "CDC Guidance for Evaluating Health-Care Personnel for Hepatitis B Virus Protection and for Administering Postexposure Management: Morbidity and Mortality Weekly Report," Recommendations and Reports, vol. 62, no. 10, 2013.

[14] FMOH, Infection prevention guidelines for Healthcare Facilities in Ethiopia. Infection prevention principles, Addis Ababa: Ethiopian Federal Democratic Republic Ministry of Health, 2004.

[15] E. Tsega, "Epidemiology, prevention and treatment of viral hepatitis with emphasis on new developments," Ethiopian Medical Journal, vol. 38, pp. 131-141, 2000.

[16] K. Yimer, erological and Molecular Characterization of Hepatitis $B, C$ and D Viruses Infections among Health Professionals in Ras Desta and Tikur Anbessa ospitals, Addis Ababa, Ethiopia, in Medical microbiology 2008, Addis Ababa University Addis Ababa, Addis Ababa, East Africa, 2008, http://etd.aau.edu.et/handle/ $123456789 / 2922$.

[17] B. E. Feleke, "Low coverage of hepatitis B vaccine and determinants among health professionals working in Amhara regional state hospitals, Ethiopia," Journal of Public Health in Africa, vol. 7, no. 2, article no. 553, 2016.

[18] G. Abeje and M. Azage, "Hepatitis B vaccine knowledge and vaccination status among health care workers of Bahir Dar City Administration, Northwest Ethiopia: A cross sectional study," BMC Infectious Diseases, vol. 15, no. 1, article 756, 2015.

[19] M. B. Ayalew and B. A. Horsa, "Hepatitis B Vaccination Status among Health Care Workers in a Tertiary Hospital in Ethiopia," Hepatitis Research and Treatment, vol. 2017, pp. 1-8, 2017.

[20] T.-A. Abebaw, Z. Aderaw, and B. Gebremichael, "Hepatitis $B$ virus vaccination status and associated factors among health care workers in Shashemene Zonal Town, Shashemene, Ethiopia: A cross sectional study," BMC Research Notes, vol. 10, no. 1, article no. 260, 2017.

[21] J. Ehreth, "The value of vaccination: A global perspective," Vaccine, vol. 21, no. 27-30, pp. 4105-4117, 2003.

[22] F. Siraj, P. Fareed, and N. Mahajan, "Assessment of knowledge attitude and practice towards hepatitis B among health care workers in a tertiary care hospital," International Journal of Reproduction, Contraception, Obstetrics and Gynecology, pp. 5861, 2016.

[23] M. T. Yousafzai, R. Qasim, and R. Khalil, "Hepatitis B Vaccination among Primary Health Care Workers in Northwest Pakistan," International Journal of Health Sciences, vol. 8, no. 1, pp. 67-76, 2014.

[24] A. Pruss-Ustün, E. Rapiti, and Y. Hutin, "Estimation of the global burden of disease attributable to contaminated sharps injuries among health-care workers," American Journal of Industrial Medicine, vol. 48, no. 6, pp. 482-490, 2005. 
[25] H. G. Ouédraogo et al., "Hepatitis B vaccination status and associated factors among health care workers in Burkina Faso," Medecine Et Sante Tropicales, vol. 23, no. 1, pp. 72-77, 2013.

[26] K. Nasir et al., "Hepatitis Vaccination among Health care workers and students of Medical College," Journal Of Pakistan Medical Association, vol. 50, no. 7, pp. 239-243, 2000, Hepatitis Vaccination among Health care workers and students of Medical College Journal of Pakistan Medical Association.

[27] R. Pathak, C. Chaudhary, D. Pathania, P. Mishra, A. Kahlon, and S. Ahluwalia, "Hepatitis B vaccine: Coverage and factors relating to its acceptance among health care workers of a tertiary care center in North India," International Journal of Medicine and Public Health, vol. 3, no. 1, p. 55, 2013.

[28] A. M. Noaman, A. E. Ahmed, and S. A. Alanee, "KAP study about Hepatitis B among Medical and Para Medical staff in Tikrit city," Tikrit Medical journal, vol. 18, no. 2, pp. 261-268, 2012.

[29] S. R. Alnoumas, F. A. Enezi, M. M. Isaeed, G. Makboul, and M. K. El-Shazly, "Knowledge, attitude and behavior of primary health care workers regarding health care-associated infections in Kuwait." Greener Journal of Medical Sciences, vol. 2, no. 4, pp. 092-098, 2012.

[30] V. Singhal, D. Bora, and S. Singh, "Prevalence of Hepatitis B Virus infection in Healthcare Workers of a Tertiary care centre in India and their vaccination status," Journal of Vaccines and Vaccination, vol. 2, no. 2, 2011.

[31] A. Fatusi, A. Esimai, A. Onayade, and O. Ojo, "Aceptance of Hepatitis B vaccine by workers in a Nigerian Teaching Hospital," East African Medical Journal, vol. 7, pp. 608-612, 2000.

[32] S. Hussain, N. Asher, and P. Shams, "Hepatitis B and C Prevalence and Prevention Awareness among Health Care Workers in a Tertiary Care Hospital," in Proceedings of the International Journal of pathology, vol. 8, pp. 16-21, 2010.

[33] R. Hesham et al., "Hepatitis B Immunization Status among Health Care Workers in Two Kuala Lumpur Hospitals," Medical Journal of Malaysia, p. 60, 2005.

[34] H. Ziglam, M. El-Hattab, N. Shingheer, A. Zorgani, and O. Elahmer, "Hepatitis B vaccination status among healthcare workers in a tertiary care hospital in Tripoli, Libya," Journal of Infection and Public Health, vol. 6, no. 4, pp. 246-251, 2013.

[35] M. A. Biset, B. Adugna, N. Getachew, S. Amare, and A. Getnet, "Knowledge and attitude of health care professionals regarding hepatitis B virus infection and its vaccination, University of Gondar Hospital, Ethiopia," Hepatic Medicine: Evidence and Research, vol. Volume 8, pp. 135-142, 2016.

[36] S. Attaullah, S. Khan, Naseemullah et al., "Prevalence of HBV and $\mathrm{HBV}$ vaccination coverage in health care workers of tertiary hospitals of Peshawar, Pakistan," Virology Journal, vol. 8, article no. $275,2011$.

[37] G. Afework, Knowledge, attitude and practice of hepatitis B virus and its vaccination among health care professionals in selected public hospitals of Addis, Ethiopia, Ababa, Addis Ababa university, Ethiopia, East Africa, 2015.

[38] H. O. P. Tatsilong, J. J. N. Noubiap, J. R. N. Nansseu et al., "Hepatitis B infection awareness, vaccine perceptions and uptake, and serological profile of a group of health care workers in Yaoundé, Cameroon," BMC Public Health, vol. 16, no. 1, article no. 706, 2016.

[39] N. Z. Janjua, M. I. Khan, and B. Mahmood, "Sharp injuries and their determinants among health care workers at first-level care facilities in Sindh Province, Pakistan," Tropical Medicine \& International Health, vol. 15, no. 10, pp. 1244-1251, 2010.
[40] N. Mungandi, M. Makasa, and P. Musonda, "Hepatitis B vaccination coverage and the determinants of vaccination among health care workers in selected health facilities in Lusaka district, Zambia: An exploratory study," Annals of Occupational and Environmental Medicine, vol. 29, no. 1, article no. 32, 2017.

[41] D. Kisic-Tepavcevic, M. Kanazir, T. Gazibara et al., "Predictors of hepatitis B vaccination status in healthcare workers in Belgrade, Serbia, December 2015," Eurosurveillance, vol. 22, no. 16, 2017.

[42] R. C. Ibekwe and N. Ibeziako, "Hepatitis B vaccination status among health workers in Enugu, Nigeria," Nigerian Journal of Clinical Practice, vol. 9, no. 1, pp. 7-10, 2006.

[43] D. Ogoina, K. Pondei, B. Adetunji, G. Chima, C. Isichei, and S. Gidado, "Prevalence of hepatitis B vaccination among health care workers in Nigeria in 2011-12," International Journal of Occupational Medicine and Environmental Health, vol. 5, no. 1, pp. 51-56, 2014. 


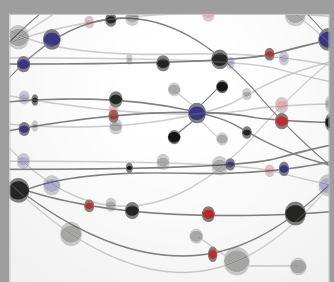

The Scientific World Journal
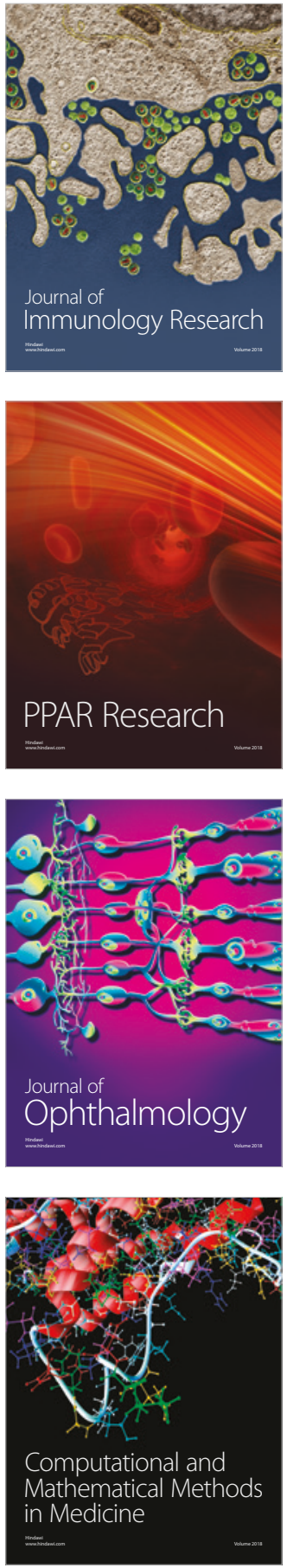

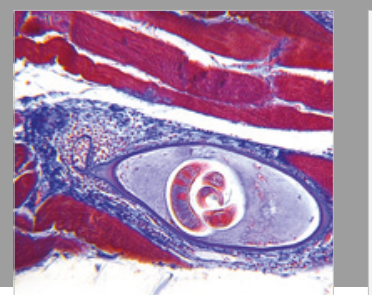

Gastroenterology Research and Practice

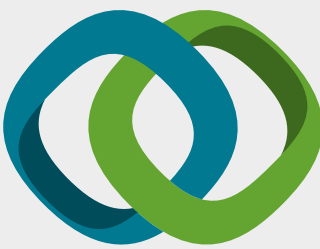

\section{Hindawi}

Submit your manuscripts at

www.hindawi.com
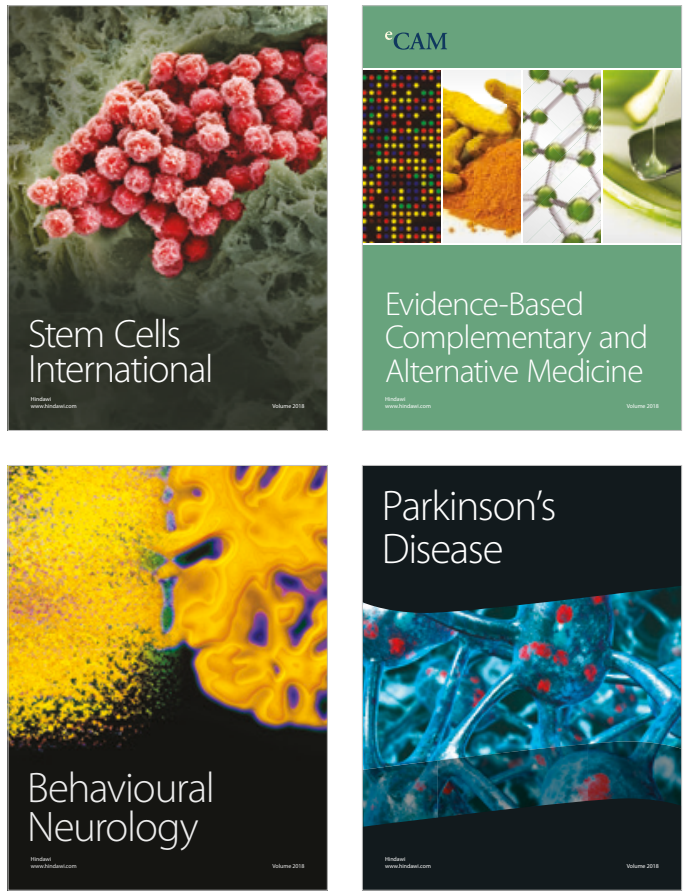

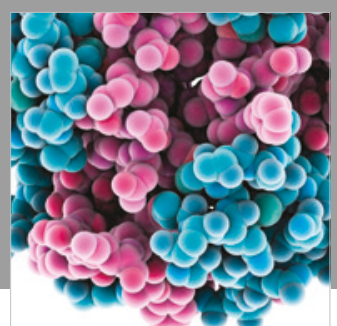

ournal of

Diabetes Research

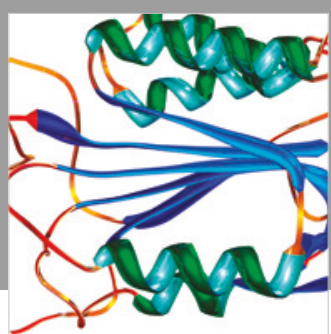

Disease Markers
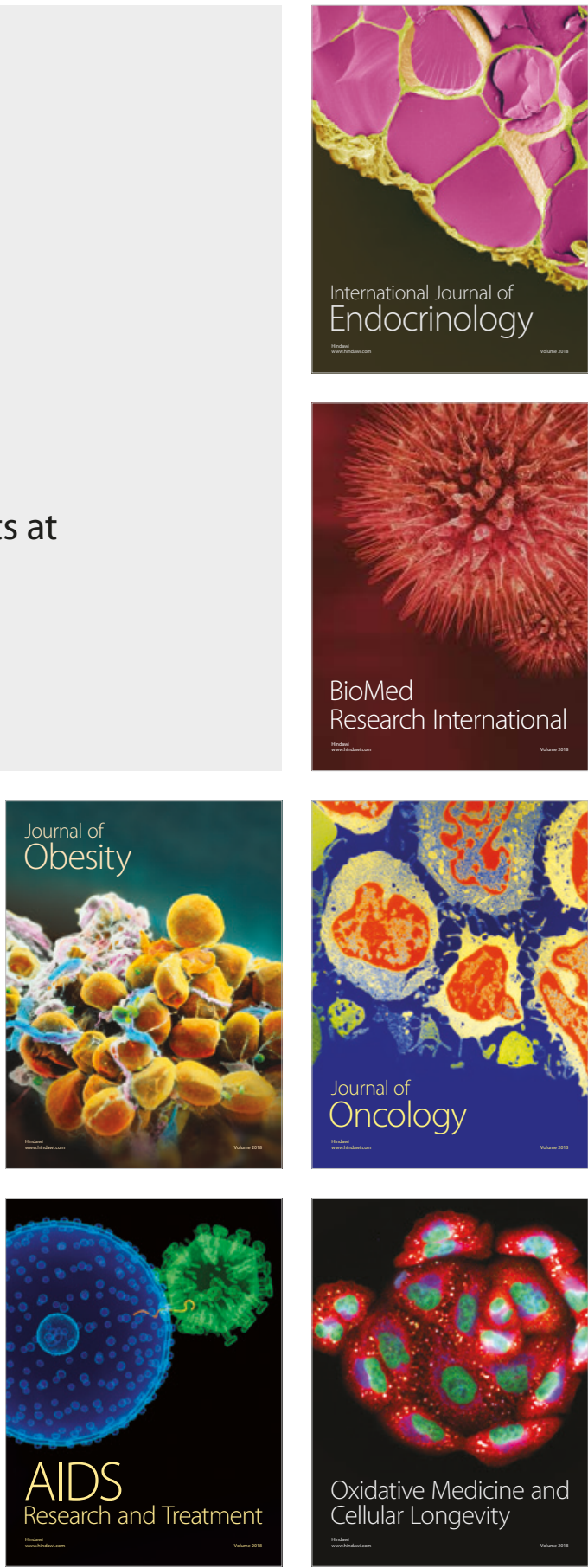